\title{
UMA ANÁLISE DOS ASPECTOS PROMISSORES DO USO DA TECNOLOGIA DA INFORMAÇÃO E DA INTERNET NO GOVERNO BRASILEIRO.
}

Luiz Alberto Lira ${ }^{1} \&$ Roque Pereira Batista ${ }^{2}$

\section{INTRODUÇÃO}

As sociedades democráticas estão se mobilizando no sentido de que os administradores públicos apóiem a transparência sobre suas ações e responder melhor aos novos tempos, nesse aspecto, estão sendo introduzidas, uma série de modificações nos governos, com uso intensivo da tecnologia da informação e da Internet. Essas ações podem ser chamadas de Governo Eletrônico.Atuando junto ao cidadão, na melhoria da sua própria gestão interna e na integração com parceiros e fornecedores, o Governo Federal tem procurado ser um exemplo indutor para a sociedade na utilização de documentos eletrônicos e novas aplicações de suporte aos processos de trabalho. Hoje, mais de 4000 sites governamentais na Internet, reunidos na Rede Governo prestam serviços ao cidadão.

\section{O PAPEL DO SERPRO NO ESFORÇO PARA IMPLANTAR O GOVERNO ELETRÔNICO}

Os Governos, de forma geral, e especialmente os Governos Federais, nos países federativos, são essencialmente organizações que lidam com informação. Tratando-se de uma organização que o funcionamento é baseado no uso da informação e do conhecimento. O SERPRO é um provedor de serviços de Tecnologia da Informação, portanto, o seu papel na implantação do Governo- Eletrônico é muito significativo, atendendo demandas e ofertas de serviços voltados essencialmente para a transparência do Governo Federal.

Outro aspecto fundamental nesse processo diz respeito à importância da certificação digital, que estabeleceu uma nova oferta de serviços baseados nas redes de comunicação. Antes da certificação, os recursos utilizados, baseados nas senhas, eram limitados em alguns aspectos de segurança e apresentavam algumas dificuldades de distribuição e gerenciamento. Com a certeza de identidade dos operadores e da garantia, muitos novos serviços poderão ser oferecidos. Para as empresas prestadoras de serviços

\footnotetext{
${ }_{1}^{1}$ Mestrando em Administração Empresarial, FGV/RJ. Professor do Curso de Administração - F TB/DF

${ }^{2}$ Aluno do 5ํㅗ semestre de Administração - FTB/DF
} 
na área de tecnologia de informação, como é o caso do SERPRO, a certificação digital abre um novo leque de oportunidades.

Busca- se também, evidências de como a construção das competências da empresa, foram influenciadas pela utilização de instrumentos diversos de aprendizagem, em seus diferentes níveis (interno e externo), para tanto a análise sobre estas implicações baseia-se na estrutura proposta por Figueiredo (2001), que distingue os processos de aquisição e de conversão de conhecimento observadas nas organizações e na matriz de Competências Tecnológicas, que apresentamos a seguir e que ilustram os processos do SERPRO.

\section{LEVANTAMENTO DAS COMPETÊNCIAS TECNOLÓGICAS DO SERPRO}

\section{Empresa:}

Serviço Federal de Processamento de Dados - SERPRO

\begin{tabular}{|c|c|c|}
\hline \multirow[b]{2}{*}{$\begin{array}{l}\text { Níveis de } \\
\text { Competências Tecnológicas }\end{array}$} & \multicolumn{2}{|l|}{ Atividades } \\
\hline & $\begin{array}{l}\text { Desenvolvimento de } \\
\text { Sistemas de Informação }\end{array}$ & Engenharia de Redes \\
\hline \multirow[b]{2}{*}{ Básico } & ROTINA & ROTINA \\
\hline & 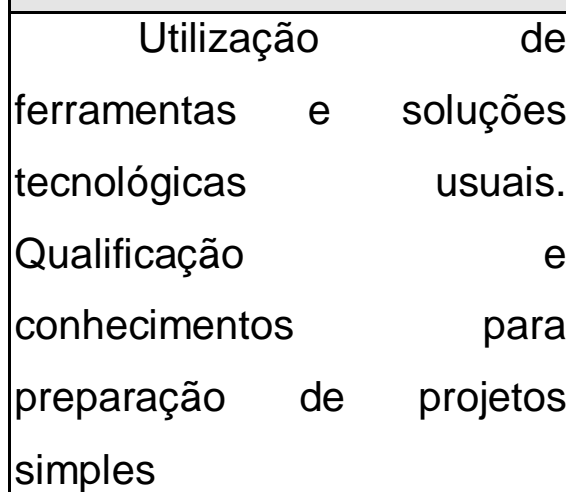 & $\begin{array}{l}\text { Engenharia operacional e } \\
\text { capacidade para resolução de } \\
\text { pequenos problemas de } \\
\text { adequação entre equipamentos e } \\
\text { linguagens de transmissão de } \\
\text { dados. }\end{array}$ \\
\hline \multirow[t]{3}{*}{ Extra-Básico } & $\begin{array}{l}\text { Qualificação para } \\
\text { projetos complexos e de } \\
\text { integração de sistemas e de } \\
\text { soluções. Certificação de } \\
\text { fornecedores internacionais e } \\
\text { de qualidade de serviços. }\end{array}$ & $\begin{array}{l}\text { Adaptações } \\
\text { aprimoramentos em equipamentos } \\
\text { de comunicação de dados. } \\
\text { Projetos integrados e de protocolo } \\
\text { combinando sistemas } \\
\text { linguagens diferentes. }\end{array}$ \\
\hline & INOVADORAS & Prospecção e utilização de \\
\hline & & 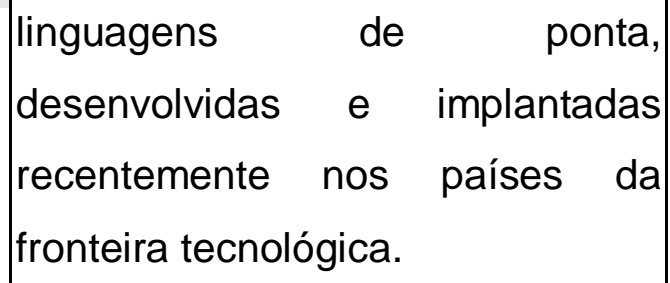 \\
\hline
\end{tabular}




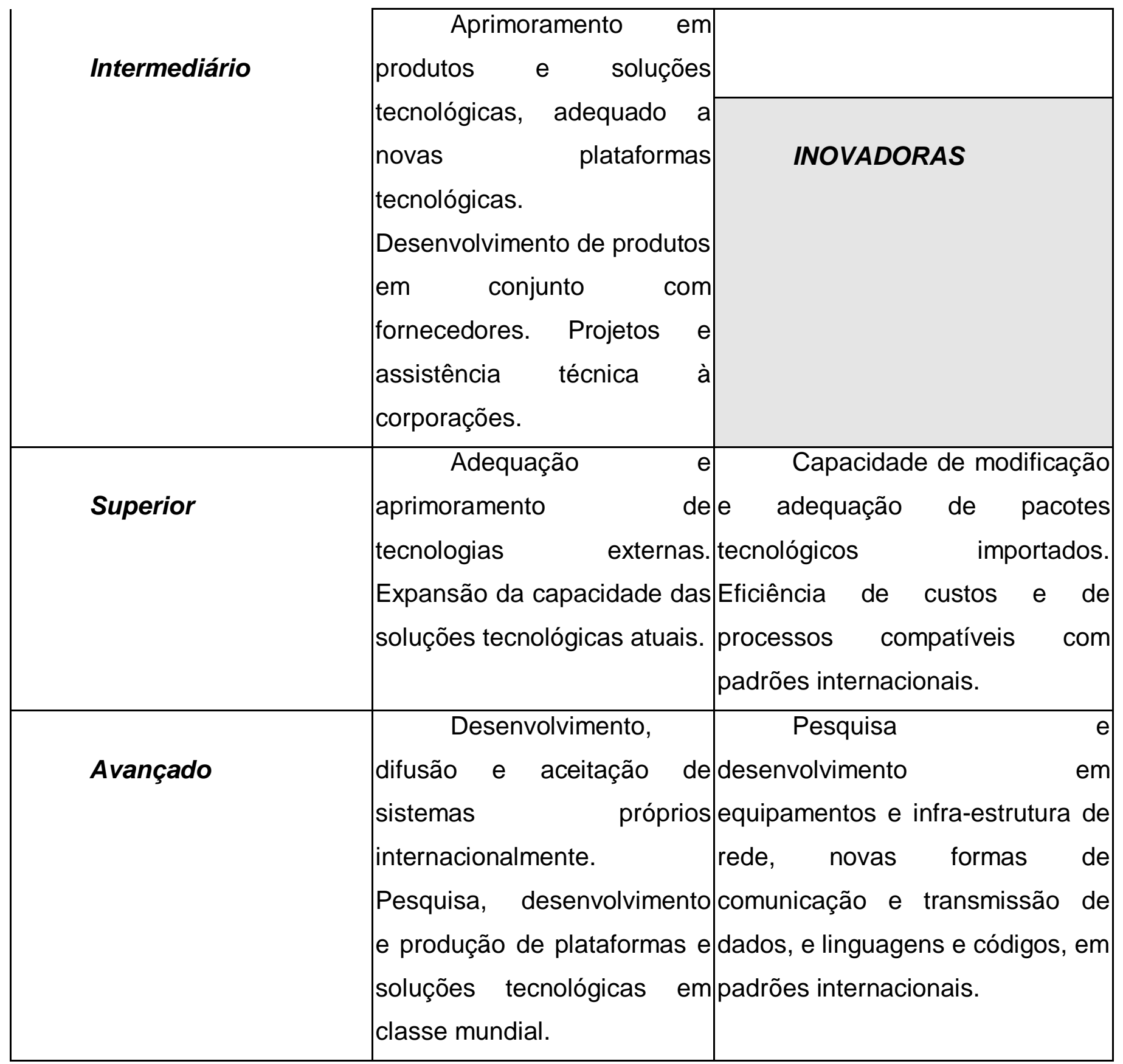

\section{OS GASTOS COM TECNOLOGIA DA INFORMAÇÃO NO BRASIL}

Os gastos com Tecnologia da Informação no Brasil, ultrapassam a marca de 2,1 trilhões e devem crescer ao nível de 50\% por volta de 2004. De acordo com estudo da World Information Technology and Services Alliance, tais despesas representam, hoje, 6,6\% do PIB mundial. O Brasil é o sexto País da lista encabeçada pelos Estados Unidos (com U\$\$ 762 bilhões ) e está à frente da Itália e do Canadá, por exemplo.

O Governo Federal, é o principal consumidor de Tecnologia. No ano de 1999 foram gastos 1 bilhão e 200 milhões de reais com informática e telecomunicações. Atualmente o 
Governo gasta cerca de $R \$ 1,5$ bilhão com aquisição de software e serviços de TI para todos os órgãos. É uma preocupação do Governo estar atualizado com o que há de melhor em Tecnologia de Informação.

\section{LINHAS DE AÇÃO DO PROGRAMA SOCIEDADE DA INFORMAÇÃO}

O Programa Sociedade da Informação está estruturado em sete linhas de ação, que indicam as principais direções dos projetos: Mercado, trabalho e oportunidades, universalização de serviços e formação para a cidadania, Educação na Sociedade da Informação, Conteúdos e identidade cultural, Governo ao alcance de todos, P\&D, Tecnologias-chave e aplicações, Infra-estrutura avançada e novos serviços. capacitação dos professores, auto-aprendizado e certificação em tecnologias de informação e comunicação em larga escala; implantação de reformas curriculares visando o uso de tecnologias de informação e comunicação em atividades pedagógicas e educacionais, em todos os níveis da educação formal.

\section{INOVAÇÕES NO SETOR DE COMPRAS DO SETOR PÚBLICO}

Essa parece ser uma iniciativa clara, baratear os custos da União ao realizar licitações para a contratação de produtos e serviços comuns. Além disso, o Governo entende que essa é a melhor forma de inserir as empresas distantes do sistema de compras do eixo de maior concentração do mercado fornecedor, uma vez que todas as informações referentes à licitação são amplamente divulgadas pela Internet, com a participação aberta a qualquer interessado.

O Último avanço do sistema de compras governamentais foi introduzido pelo decreto № 3.722, que regulamenta o art. 34 da lei № 8.666/93, e dispõe sobre o cadastro e regularidade de fornecedores para as licitações públicas. Publicado no Diário oficial de 10 de janeiro de 2001, o decreto torna obrigatório o cadastro e regularidade junto ao Sistema de Cadastramento Unificado de Fornecedores - SICAF para qualquer empresa interessada em negociar com a Administração direta, autárquica e fundações.

\section{ASPECTOS CONCLUSIVOS}

As relações do Estado com a sociedade se concretizam em duas vertentes, onde, em primeiro lugar, o Estado, por meio do governo, persegue objetivos estabelecidos pelos cidadãos e que devem ser alcançados na forma de políticas públicas tais como políticas monetária, fiscal, sanitária, previdenciária, de transportes, de desenvolvimento, defesa do 
consumidor, entre as inúmeras que hoje em dia compõem o leque de áreas de atuação do Estado.

Numa segunda vertente, principalmente em função das políticas públicas adotadas pelo Governo, o Estado, por meio da Administração Pública, presta ou cria condições para fazer chegar à sociedade os serviços desejados variados e direcionados a diversos públicos: O cidadão, as empresas, outros governos externos e internos.

A intensificação do uso da Tecnologia da informação e comunicações (TIC), durante a segunda metade da década de 1990, tem permitido um ganho efetivo de eficácia e eficiência. Um dos indicadores que demonstram esse fato é o número de funcionários públicos federais, que, com um contingente de cerca de $55 \%$ dos ativos de 1990, a Administração Pública realiza as mesmas funções nesta virada de milênio, sem substancial variação de qualidade e a um custo menor.

O que faltava ao Governo, entretanto, era uma estratégia para ocupação desse novo cenário virtual. No contexto do e-gov, tal estratégia passa pelo provimento de serviços à sociedade nos meios de G2C (relacionamento governo/cidadão) e G2B/G2I (governo com as empresas e a comunidade financeira), bem como o interno G2G (Governo se relacionando internamente ou entre níveis e esferas). Assim o governo tratou de delimitar ações a serem desenvolvidas para a efetivação dessas e essa tarefa foi consolidada por meio da criação do Grupo de trabalho Interministerial, para propor novas formas eletrônicas de interação, conhecido por GTTI. A proposta, que reúne os projetos do Governo Eletrônico, consiste em metas a serem atingidas até 2006 e foi aprovada em agosto, pelo Presidente da República. O Governo Federal agora passa para a fase de implantação deste conjunto de projetos do e-gov, por meio do Comitê Executivo do Governo Eletrônico.

\section{BIBLIOGRÁFIA}

ALBERTIN, Alberto L. Pesquisa de Comércio Eletrônico no Mercado BrasileiroCIA/EAESP/FGV,São Paulo,2000.

ALBERTIN,Alberto Luiz.Administração de Informática,São Paulo,Editora Atlas,1999.

BRASIL. Serviço Federal de Processamento de Dados. Banco de Inovações. Informativo. Brasília: 2000

BRASIL. Serviço Federal de Processamento de Dados.Decisão de Diretoria no 1, de 30/06/1997. Documento Normativo que instituiu o Modelo Conceitual de organização e Gestão do SERPRO.Brasília:1997

BRASIL.Ministério da Ciência e Tecnologia.Livro Verde.Homepage, 2002

BRASIL.Ministério do Planejamento e Orçamento www.redegoverno.gov.br, 2002

FIGUEIREDO, P..N. Acumulação de Competências Tecnológicas e Processos de Aprendizagem: Estruturas conceituais e experiências de empresas no Brasil. Extraído e 
adaptado de FIGUEIREDO, P.N..Tecnologic Learning and Competitive Performance. Cheltenham, UK \& Northampton, MA, USA: Edward Elgar Publishing Ltd: 2001

FIGUEIREDO: P. C. N. Acumulação de capacidade tecnológica nas empresas brasileiras: Subsídios para o seu gerenciamento. Artigo baseado na dissertação de mestrado do autor. XVIII Simpósio de Gestão da Inovação Tecnológica.São Paulo:1994

I.TURBAN,Efrain. Eletronic Commerce: a Managerial Perspective. Prentice Hall, Inc. NJ 07458

MARTINS, Gilberto de Andrade. Manual para elaboração de monografias e dissertações.2.ed.São Paulo:Atlas,2000

MEIRELLES, Fernando S.Informática nas Empresas : Perfil, índices, Custos e investimentos - publicado em CAMPOS, Rui -Fatos e Números em informática no Brasil -Fenasoft, São Paulo:1998.

VERGARA,S. C. Projetos e relatórios de pesquisa em Administração. São Paulo:Atlas,2000 